\title{
Business Process Risk Modelling in Theory and Practice
}

\author{
DOI: 10.12776/QIP.V25I1.1551
}

\author{
Miroslav Špaček
}

Received: 2021-03-02 Accepted: 2021-03-23 Published: 2021-03-31

\begin{abstract}
Purpose: The purpose of the paper is to introduce SW based decision-making tool that helps managers cope with risks and uncertainties of selected industrial processes. The solution is substantiated by the theoretical background.

Methodology/Approach: The research is based on combination of contextual interviews with process management experts and Business Process Modelling Notion (BPMN). The former is aimed at the identification of industrial processes with highest risk exposure the latter is conducive to the design of processes to be subjected to stochastic simulation.

Findings: The findings show that the risks and uncertainties in the management of industrial processes can be kept under control when using advanced tools of risk analysis as simulation approaches. The solution proposed comes in handy to risk analysts or process managers.
\end{abstract}

Research Limitation/Implication: The library of process models which were included into stochastic simulation includes selected processes as investments, service providing or economic value-added engineering. Additional processes are being included on ongoing basis.

Originality/Value of paper: The paper offers the solution to industrial process risk management which goes far beyond academic sphere and provides industrial practitioners SW tool that facilitates process risk management.

Category: Technical paper

Keywords: process modelling; probabilistic approach; stochastic simulation 


\section{INTRODUCTION}

Industry 4.0 can be interpreted as a digitalization of a material production that is propelled by cybernetic systems in the environment of Internet of Things (IoT). In the Industry 4.0 era, intelligent analytics and cyber-physical systems are teaming together to realize a new thinking of production management and factory transformation. IoT is composed of two main parts which are Internet of services and Internet of media. This facilitates the transformation of processes from their generic versions to customizable ones as well as the transformation from partial participation to full participation in the production (Zhang, Liu and Tang, 2014). The core of Industry 4.0 will become a Factory 4.0 which is expected to produce and deliver products that are not encumbered by increasing costs. In this way, series production will be combined with line-level personalization (Kagermann, Wahlster and Helbig, 2013). Within Industry 4.0 intelligent products are permanently identifiable and localizable. Terms like „intelligent production", "intelligent factory" or "smart factory" are now commonly used in Europe (Smit et al., 2016). The President's Council of Advisors on Science and Technology in the United States advised the Government to implement an advanced manufacturing strategy, which was accompanied by a national strategy plan one year later (Prause and Weigand, 2016). Chinese version of Industry 4.0 is termed "Made in China 2025" (China Academy, 2016; Hao et al., 2017). Similarly, Russian government has been prioritizing advanced production since 2013 (Dezhina, Ponomarev and Frolov, 2015). Basically, the concept of Industry 4.0 deals with the creation of a novel manufacturing paradigm and environment comprising intelligent and selfcontrolling objects. Smart products are constantly identifiable, steadily locatable, as well as aware of their latest condition and alternative paths to their destination (Ramsauer, 2013). In the vision of an extensive penetration with this manufacturing approach, orders guide themselves through entire value chains autonomously and machines set-up automatically as well as reschedule the production on their own, if an error is predicted (Kaufmann, 2015). Smart factories handle complexity and they are less vulnerable to losses of production. In addition, resource efficiency in terms of material usage, energy consumption, and human work is significantly enhanced (Wildemann, 2014). Nowadays, smart factories focus mostly on control-centric optimization and intelligence. Moreover, greater intelligence can be achieved by interacting with different surrounding systems that have a direct impact on machine performance. Achieving such seamless interaction with surrounding systems turns regular machines into self-aware and self-learning machines, and consequently improves overall performance and maintenance management. Transformation from today's status into more intelligent machines requires further advancement in the science by tackling several fundamental innovations (Lee, Kao and Yang, 2014). Current business operations within a framework of Industry 4.0 are confronted by high risks and uncertainties. 
Despite these problems it is imperative for the company management to create the value for both customers and shareholders. Capability to manage companies in periods of breakthrough business discontinuities remains highly valuated managerial competence. From this point of view, it is very demanding for company managements to challenge these risks and uncertainties. Risks and uncertainties are usually bundled into the term risk factors. By the term risk factor management usually understands stationary or non-stationary phenomenon which may be the source of danger (Tichý, 2006). These risk factors may change both continuously and discontinuously depending on the nature of the parameter in question. Typically, some of them like price or output quantity may change continuously while others like facility size discontinuously. Individual risk factors usually operate with varying intensity and they are very often statistically dependent. Moreover, the company can be exposed to varying externalities that may exert negative effects on company performance. These externalities include ongoing pandemic threat, climate changes, migration or global financial crisis, regional or global political instability, population aging and other. Even under these worsened condition when the risk factors are not only dependent on each other but also difficult to predict the managers are compelled to make reasonable managerial decisions. At these circumstances the managers are unable to incorporate all these uncertainties into decision-making process and incline to intuitive decisions that are often imprecise or even completely faulty. The inability of the managers to make right decision at these complex situations is considered the main problem that triggered this type of research. The practice shows that there are no trivial means that would significantly improve the quality of managerial decision-making. Possible way out of this problem is using advanced tool of risk management like probabilistic approaches that may take into account both continuous character of risk factors and their stochastic dependence. The paper submitted offers a rational approach to the management of business processes where purposefully designed software solution facilitates decision-making processes upon the inclusion of concomitant risk and uncertainties. The main goal of the research was to design industrially applicable software tool that would be able to analyse key business risks, determine the severity of the impact of risk factors on main performance characteristics and contribute to search for optimum decisions which are conducive to entrepreneurship sustainability. Supporting goal is the identification of a generic set of business processes the variability of which can undesirably decrease overall company performance. One of the tools that has been already implemented in decision-making practice in both financial and industrial sector is Monte Carlo simulation which has been attracting certain popularity since the War II. (Silva, de Abreu and de Amorim, 2019). This paper aims at the development of software based decision-making tool that would simplify and facilitate key managerial decisions. The concept comes out of Business Model Canvas (BMC) that comprises nine underlying factors that are decisive for running operable business model. These factors include key partners, key activities, key resources, cost structure, value proposition customer relationships, 
customer segments, channels and revenue streams (Osterwalder and Pigneur, 2010). Based on the literature search and preliminary contextual interviews with risk management experts following research question was raised: (RQ) In what extent can company risk management processes be computerized to effectively contribute to company financial performance?

\section{METHODOLOGY}

As an approach of choice triangular approach was selected. This methodological approach is based on the combination of several data sources, research methods, investigators, and theoretical schemes (Wang and Duffy, 2009). At first the methodology was based on extensive content analysis that enabled to identify practices that routinely apply probabilistic approaches to risk analysis, processes modelling or business model development. Following terms were subjected to literature quest: business model simulation, business process modelling and business process management. Furthermore, six contextual interviews with risk managers or specialists were conducted. Contextual interview was preferred to other research methods (including quantitative questionnaire survey) due to its flexibility to go deeper into details if some interesting information occurred during the interview. Direct contact with respondents enabled to repeatedly ask "why" if currently discussed problem required further explanation. Interviewed persons were purposefully selected to represent service and production sector in the equal proportion. Each interview lasted from 40 to 50 minutes Research team gave priority to semi-structured interviews which proved to be comfortable for interviewed persons. Contextual interviews were recorded manually. The interviews focused on following points: (i) processes that are essential for company business, (ii) the approaches to the assessment of process risks (iii) risk measurement and (iv) risk mitigation provisions that company actually applies. Finally, the interviewees were allowed to make a final review of recorded interviews to prove that the notes were made correctly. Interviews coding was carried out as per Campbell et al. (2013). The execution of contextual interviews with company practitioners led to the identification of company processes that are exposed to the highest risk. It dealt with investment process, new product development, launch of a new product, ways of product delivery, increase in production capacity etc. Contextual interviews furthermore enabled the research team to develop generic BMC that specified key processes for selected categories of BMC. Furthermore, these processes were decomposed to sub-processes and activities. It helped the team exactly describe the activities which were further subjected to modelling. The most appropriate approach to activities description proved to be graphic presentation of activities. This way of presentation is quite illustrative and understandable. Research team chose BPMN because of several reasons: the first reason rests in fact that this approach is proven, quite flexible, illustrative and easily adaptable to almost any type of organization. The second reason is the flexibility of the language that comprises broad scale of elements that are able to precisely capture the nature of workflow. It encompasses initial 
events that are the trigger points of the process in question. Activities and intermediate events represent the events themselves and activities of the process. By means of end events it is possible to express the outcome of the process. Processes management is executed through decision-making gates. Generally defined standard of elements encompasses the set of parameters that ensure one of the most relevant capability that is starting the process. Aforementioned capability can be used with advantage for simulation modelling. By this way it is possible to incorporate the specifics of individual organizations into simulation modelling. BPMN thus enabled to design usual (generic) company processes in their mutual interconnection including subprocesses and activities. In addition, stochastic simulation appeared to be the method of choice because of its easiness and smooth adaptability to actual managerial practices that undergo almost permanent change. Stochastic simulation is based on exactly identified risk factors that represent the input variables. Risk factors were identified either by sensitive analysis or expert opinion. The former was conducted by stepwise testing the change of a chosen output variable (Net profit, value added, Net Present Value) in dependence to the incremental change of input variable (sales volumes, unit price, material, energy or personnel costs, investment expenditures, production capacity etc.). The latter refers to expert opinion which may also include creative methods application. For this reason, established creative methods like brainstorming, brainwriting, Crawford Slip or Delphi were used (Al Badi, 2019). Risk factor identification process was accomplished by the validation of findings by means of contextual interviews with the experts familiar with process management. The experts (company managers, investment managers) validated the findings based on critical assessment and comparison with their own management practices.

\section{LITERATURE REVIEW}

\subsection{Risks and Their Identification, Analysis and Mitigation}

To treat risk factors properly it is inevitable to identify, analyse, measure, and finally mitigate the risks. For the risk identification various creative methods are recommendable (influence diagrams, brainstorming, checklist, Delphi method (Špaček and Červený, 2020; Silverstein, Samuel and Decarlo, 2012). Faulty or incomplete risk factors identification can substantially undermine effective risk management (Crouhy, Galai and Mark, 2014). Practical management offers various tools that may be conducive both to effective risk analysis (sensitivity analysis, risk matrix) and risk measurement (variance, standard deviation, value at risk). Managerial characteristics of risk are also very popular among company managers (e.g., probability of overcoming certain value or probability of not reaching certain value). Company management often faces problem to make key decisions when the decision is affected by high number of risk factors, their continuous character and eventually by their mutual stochastic dependence. New 
investments, new product development, replacement of obsolete facilities, increase in production capacity, penetration new market, extension of product line or divestment of the part of business can be ranked among decisions of this type.

\subsection{Business Models and Their Role in Supporting Company Performance}

Business model (BM) can be viewed from several standpoints. There are a lot of definitions in scientific literature. The most common is that posted by Osterwalder and Pigneur (2010, p.14): "A business model describes the rationale of how an organization creates, delivers and captures value." Similarly, Davila, Epstein and Shelton (2012) presents definition of a business model as a description how the company creates, sells, and delivers value to its customers. Magretta (2002, p.87) perceives BM in a more sensitive way. According to her "business models are at heart, stories - stories that explain how enterprises work". There is an effluent scientific literature aimed at BM development. Gassmann, Frankenberger and Csik (2014) surprisingly came with an idea that many of existing BM are the plain replication of existing ones. According to them there are only $55 \mathrm{BMs}$ which can be considered original. The rest of them are their adaptations and modifications. Structure of BM which is now accepted by the communities of business professional is quite close to BMC introduced by Osterwalder and Pigneur (2010). Organizations aim to improve their processes through frequent adaptation of new business models that can serve and cope with emerging needs (Tbaishat, 2017).

\subsection{Business Process and Its Modelling}

Damij et al. (2016) came out with the definition of a business process: "A Business Process (BP) is defined as a collection of related and structured activities with the aim to create outputs that are produced to serve customers." It is apparent that BP is perceived as a key value driver that must be distinguished from other organizational arrangements. BPs represent an essential part of every organization regardless of size and industry. The clarity of their definition and their regular optimization is essential for overall success of the company. The optimization of BPs is critical for the company and requires proper application of modelling techniques and suitable simulation tools. Business Process Modelling (BPM) is the set of technologies and standards for the design, execution, administration, and monitoring of business processes (Harvey, 2005). BPM also improves quality of information system development. It enables to increase the integrity between business operations and information systems through visualization of business requirements (Kumagai, Araki and Ono, 2014). BPM allows organization to gain insight, reduce risk, and potentially optimize process. It provides a framework from which key risk and performance indicators can be identified and utilized to indicate quality process performance supposing that process metrics fall within pre-specified tolerance limits. It also provides the 
framework into which process control for monitoring, adjusting, and controlling the output of a process can be added (Cernauskas and Tarantino, 2009). In addition, BPM helps understand the organization's work, comprehend the process in detail and then use technological support for improvements to human activities (Tbaishat, 2017). In general, BPM is understood to be a corner stone to help managers improve operational performance but on the other hand it appeared to be insufficient to help organizations face the awesome challenge of competitiveness in a constantly changing environment (Nurcan et al., 2005). The purpose of BPM is to develop a model that reflects the organization functionality of existing or newly established business processes and can be considered a predecessor to business process simulation that is carried out by using simulation tools or software. The goals of BPM were specified by Curtis, Kellner and Over (1992) as facilitation of human understanding and communication, support process improvement, support process management, automation of a guidance in performing process, and automation of execution support. Similarly, Havey (2005) specified the motivation for the execution of BPM in the way of formalizing existing process and spot needed improvements, facilitating automated, efficient process flow, increasing productivity, and decreasing head count, allowing people to solve the hard problems, and simplifying regulations and compliance issues. Apart from historical techniques like flowcharting or Integrated Definition for Function (IDEF) there are several standards to model company processes like UML (Caetano et al., 2005), XPDL, RAD (Rapid Application development) or ARIS (Architecture of Information Systems) developed by Prof. A.W. Scheer. RAD reacts to the rigidity of a classic waterfall model and accentuates the need for the adjustment of requirements as a reaction to new reality that usually come to light during the project. ARIS applies HOBE (House of Business Engineer) to address BPM in a holistic way that integrates organizational perspective with IT perspective. When collating RAD with ARIS it can be concluded that the former provides better visualisation, removes unnecessary tasks while the latter is considered rather general framework that can be used for creating models of business processes in a wider area of business analysis. ARIS provides model for creating, analysing, and evaluating the business processes (Tbaishat, 2018). The main advantage of ARIS rests in its ability to cast several views of the architecture provided, which reduces the complexity and ambiguity that is typical for other models. ARIS is able to reduce complexity by the introduction of different descriptive levels which lead the analyst from the business problem down towards technical implementation (Rippl, 2005). Visualisation of ARIS model is presented in Figure 1. 


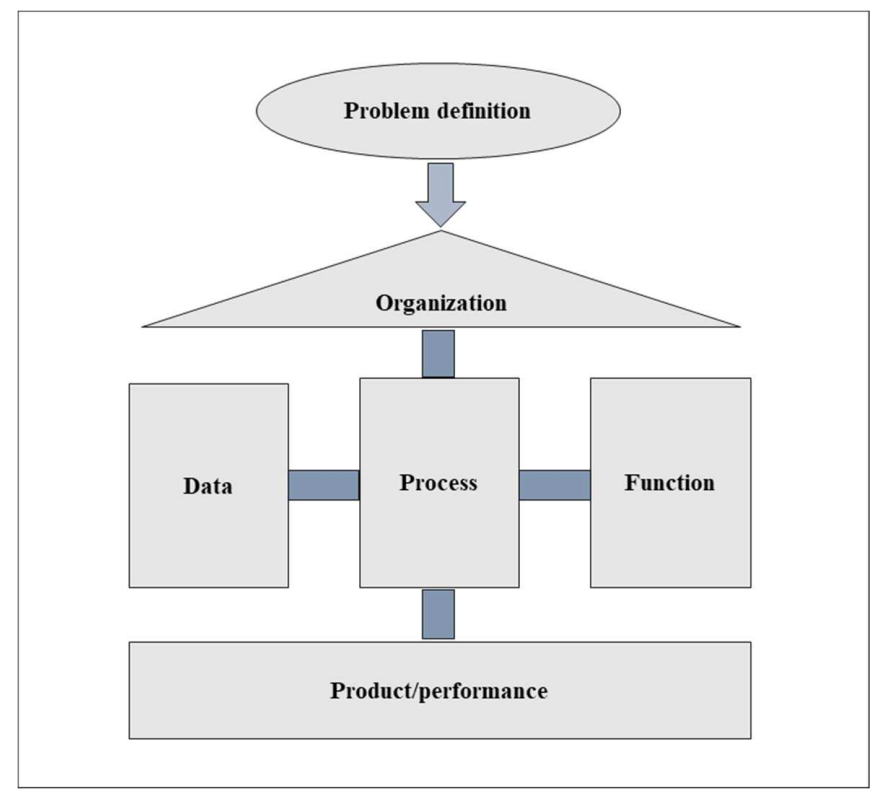

Figure 1 - The General Scheme of ARIS Architecture (ARIS HOBE) (Tbaishat, 2017)

The point of departure for the presentation of key activities by a graphic way is Standard Process Model and Notation (BPMN). This concept was brought to light in 2001 as a visual design layer for a transactional workflow system. It represents the set of principles and rules which are dedicated to graphic illustration of company processes. BPMN is a business process management standard for graphical notation that depicts the steps in a business process, providing comprehensive business process modelling capabilities to users within single environment. Graphical elements of BPMN can be split into five basic categories (Silver, 2009): flow objects, connecting objects, pools and swim lanes, data objects, artefacts ((i.e., a product created or modified by the enactment of a process element). Other components that are closely related to BPMN are processes, collaborations and choreographies. This standard is supported by wellestablished companies like IDS Sheer, Oracle, Intel, SAP, Adobe Systems etc. It simultaneously provides Exchange format that may be used for the Exchange of BPMN processes definition among different tools. Furthermore, BPMN enables smooth transfer of developed models into BPEL (Business Process Execution Language) which is receptive to other application. Both language standards come out of XML (eXtensible Markup Language). In addition, other authors prefer using strategy-driven BPM approach that better accentuate goal-perspective or the map-driven processes modelling approach (Nurcan et al., 2005). This approach interconnects goal-driven approach with proper specification of trajectories how to meet the goals (map-driven approach). Certain improvements were brought into problematics of process modelling by the introduction of hierarchical business variation analysis. This approach improves productivity of 
the model development. It enables to extract the variations of business functions and consolidate similar business functions (Kumagai, Araki and Ono, 2014). Alongside with the development of new methods of BPM there is an attempt to implement environment that would enable seamless collaboration between business and its users to develop executable business process models. One of the examples is TIBCO Business Studio TM-BPM edition 4.3.0. TIBCO Business Studio $^{\mathrm{TM}}$ is a standard-based business process modelling environment that enables business experts and process authors to collaborate to create process models, organization models, data models, forms, and page flow models. The user-specific functionality of TIBCO Business Studio enables effective collaboration between business and IT users to ensure that both parties contribute successfully to the process model in order to improve BPM implementation (TIBCO, 2020). Oracle BPM studio operates in a similar way.

\subsection{Selection of a Method}

In spite of the fact that variety of methods for BPM were mentioned in literature little attention was devoted to the assessment of their suitability. Selection of the suitable method for BPM is sometimes very tricky and existing literature does not offer precise approach for the method selection. Curtis, Kellner and Over (1992) suggested that four perspectives should be considered in BPM:

- Functional perspective - where the process elements to be performed are identified;

- Behavioural perspective - which represents a model that specifies when process elements are allocated and how related actions are performed;

- Organizational perspective - which determines who performs process elements and where;

- Informational perspective - which presents what informational entities are produced by a process (data, documents etc.).

Luo and Tung (1999) tried to set up a framework for selecting BPM method that is based on modelling objectives. This framework commences with setting the objectives that are considered underlying factors for further modelling. Modelling procedure then continues with the determination of perspectives which the processes can be viewed from. To make the modelling procedure more simplistic the authors categorize both objectives and perspectives into categories. Objectives are ranked among following categories: (a) communication, (b) analysis and (c) control. Perspectives are then ranked among categories as: (a) object, (b) activity and (c) role.

\subsection{Simulation and Scenario Approaches to BPM}

Business processes are always tied with risks that can shake their performance. Business Process Simulation (BPS) can meet several company demands in 
parallel. It is applicable for $\mathrm{BP}$ analysis that is usually performed by the simulation of BP behaviour under various conditions and potential "what-if" scenarios or sensitivity analysis prior to its implementation (Patig and Stolz, 2013). In addition, BPS is used to assist decision-making by providing a tool that allows the current behaviour of a system to be analysed and understood. It is also able to help predict the performance of that system under a number of scenarios determined by the decision maker. An important aspect of BPS is its ability to capture dynamic behaviour of the process. There are two aspects of dynamic systems that must be taken into consideration (Greasley, 2003):

- Variability - which can be manifested in both key quantitative parameters of the system (e.g., output quantity, various types of costs, unit prices etc.) and duration of the processes (e.g., time-to-launch, payback period, lead time etc.);

- Interdependence - which means mutual stochastic dependence of input variables. It is quite commonplace that many input variables are stochastically dependent (there are some correlations among input variables). Typical example is stochastic dependence between unit price and sales volume (There is empirical evidence that this correlation is negative).

Managers and risk specialists strive to use various analytical approaches to get risks under control. IBM research team developed a scenario-based method called Operational process specification methodology (OpS). This in-house elaborated approach proved to be viable at discovering opportunities for process improvement. OpS is a technique for capturing a complete operational description of a business. OpS is based on factorization of operational business knowledge into information, function, and flow components. This model was tested under various scenarios which were characterized by different process parameters like cycle time, resources, and alternate process configuration. The main outcome of model testing was finding that substantial improvement (typically overall process cycle time) can be accomplished by process changes and proper allocation of resources (Young et al., 2020). Simulation approaches are usually used in processes that are encumbered by high risks and uncertainties. Typical parameter which is essential for company financial performance is cash flow (CF). This parameter is affected by various risk factors (sales, unit prices, investment and operating costs, costs etc.). To avoid falling in insolvency proceedings companies should be able to assess and forecast company CF. Kazakova, Zayarky and Medvedev (2019) developed a system-dynamic model for predicting the financial flows of an enterprise considering the risk and uncertainty of interaction. The model foresees the regulation block of random factors affecting the interactions processes in the financial management system. Unfortunately, the model was subjected to testing on experimental level only. Simulation of investment CF carried out by Monte Carlo method has already proved its worth within risk analysis methods. This method was tested not only in the assessment of investment process economic effectiveness but also in 
decision making analysis concerning selection of production technology (Špaček, 2015; Vacík et al., 2018). Other simulation approaches were tested upon the analysis of risks and uncertainties in energy business (Praca et al., 2019). Business Process Reengineering (BPR) is considered very demanding task which require precise BPM. To get risks tied with BPR under control business process simulation was proposed as a suitable approach (Tigkiropoulos, Kyratsis and Dinopolulou, 2009). Moreover, BPS can provide support for a change process by measurement and analysis of process performance (Greasley, 2003). Heinrich et al. (2017) used simulation approach to assess mutual performance impact between BPS and information system. As for simulation software there is variety of software tools which are purposefully used for BPS. Business Model Simulation Software (BPSs) usually encompasses modelling tools (a graphical modelling environment, built-in simulation objects with defined properties and behaviour, sampling routines, property sheet and visual controls), tool to execute simulation (a simulation executive to run a model, animated graphic, virtual reality representation and user interaction with the simulation as it runs), tool to support experimentation, optimization, result interpretation and presentation, or links to other software (links to spreadsheets, databases, ERP systems etc.) (Pidd and Carvalho, 2006).

\section{DESIGN OF INNOVATIVE BPS SOFTWARE}

Simulation approaches represent advanced management tool which enhances the quality of managerial decision-making in situations when other managerial approaches fail, or their implementation is difficult from technical point of view. Basically, it deals with the situation when high number of risk factors were identified, and these risk factors are of continuous character. Simulation approach is a method of choice in case that any other analytical approaches are of no use. When solving the problem for instance by scenario approach it would necessitate the elaboration of excessive number of scenarios implementation of which would be impossible. The solution submitted is based on stochastic dependence between input variables represented by risk factors (like any input variable like costs, unit prices sales volumes, markets share, rate of production capacity utilization etc.) and output variables (like net or operational profit, cash flow, net present value etc.). In the background of the methods stands mathematical model. Mathematical description comes from stochastic dependence that is described by an equation 1 .

$$
Y=f\left(X_{1}, X_{2}, \ldots . X_{n}\right)
$$

where parameter $Y$ is output (dependent) variable and parameters $X_{1}, X_{2}, \ldots X_{n}$ are input (independent) variables. Any input variable is assigned probability distribution that is based either on historical development of the variable (e.g., unit price) or expert opinion. To make the model understandable from managerial 
point of view the authors prefer using triangular probabilistic distribution that is characterized by the lowest, the highest and the most probable value. Usually, this simplistic approach to probabilistic distribution assignment appropriately balances demandingness to operate the system in practice and reliability of the results. To make the model more reliable software developers incorporated correlation matrix into calculation. This matrix quantifies mutual dependence among input variables. Correlations among input variables (risk factors) are set on expert basis before the start of the simulation. The logic of the correlation between pairs of risk factors may be positive or negative. Moreover, the strength of correlation was quantified by means of ranking them into three levels: strong, weak and none. Needless to stress that the calculation is more sensitive to setting proper correlation than to selecting probability distribution of input variable. The nature of the simulation is the calculation of great many (round tens of thousands or even hundreds of thousands) scenarios each of them representing one discreet arrangement of the future. The simulation model repeats the calculation many times in dependence on the pre-defined number of runs. The output (dependent) variable is obtained in a form of probabilistic distribution from which it is deducible to indicate the probability of reaching desired results or the probability of overcoming desired value. BPSs incorporates pseudorandom figures generator that enables to pick up random input data for the calculation. Risk factors are determined either by sensitive analysis or expert opinion.

The BPS software development applied BPMN approach. This approach suited the purpose. Design pattern of the software solution to business model simulation is shown in Figure 2.

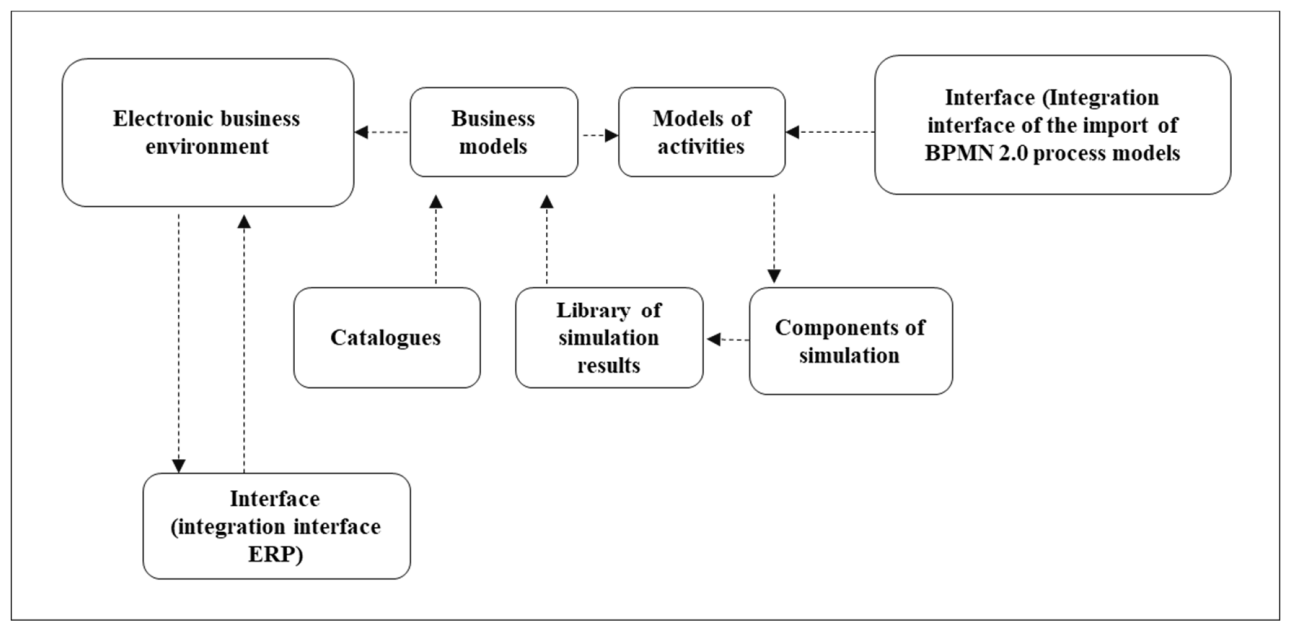

Figure 2 - Design Pattern of the Software Solution to Business Process Simulation (Own Elaboration)

Design pattern, which is presented in its simplistic form, illustrates the relationships among all components of the model. It is apparent that the core of 
the model is business model that is composed of nine subcategories as pointed out by Osterwalder and Pigneur (2010). Each subcategory comprises several activities that refer to the specific type of business. Providing that these activities are describable by a mathematical model they can be subjected to simulation.

\section{RESULTS AND DISCUSSION}

The paper offers advanced approach to the management of risks and uncertainties of business process. The approach is based on purposefully elaborated software tool that enables simulation of variety of risk factors which influence the probability distribution of dependent variable. In addition, the model takes into consideration mutual stochastic dependence of risk factors that significantly improves reliability of the model. In principle, the model enables mangers to simulate any scenario which may come into existence during the company lifetime cycle. There are also limitations to the use of this tool since the model works under proviso that the process is describable by a mathematical model. The model can be quite simple (e.g. plain calculation of profit or cash flow). On the other hand, there is a possibility to extend the model by other functionality. The model can be easily interconnected with financial analysis parameters to analyse company rentability, liquidity solvency, value creation, limits of indebtedness etc. The model is proposed to be mastered by almost any employee with adequate technical skills but the users should undergo short training in the basic statistics. Another problem may be tied with the interpretation of the results. Managers unfortunately got accustomed to understanding business process performance parameters in terms of deterministic values. When obtaining results (profit, cash flow, Net Present Value, Return on capital etc) expressed in terms of probability distribution it may cause problems with interpretation. Empirical findings derived from the software development were conducive to formulating response to RQ: Company business processes that can be easily and flexibly supported by a mathematical model are the candidates for softwarebased risk analysis. Typically, following processes can be involved into this group: new product development, investment processes, technology effectiveness assessment process, selection of alternative organizational concept (outsourcing, technology divestment, production termination etc.,), alternatives for assets financing (loan, leasing, equity funding etc). On the other hand, business processes the effects of which can be characterized by financial parameters with difficulties are not suitable adepts for SW risk modelling. Basically, it deals with uneasily measurable processes as development of employee soft skills, change in corporate culture, investments into environmental security or health and safety of employees, regulatory compliance etc. 


\section{CONCLUSIONS}

Research team offers precise and reliable software tool that enables company management team to simulate various situation which might come into effect during any business activity. The software is quite flexible and enables smooth and easy adaptation to particular condition of the company. The model was validated on the example of production, service, and trading companies. These three examples personified three main types of business entities. The software makes possible to pick up key company processes from the predefined list of generic key processes (investment process, managing customer's order, managing complaints, new product development process, supply chain management process etc.). It is at company discretion to adapt pre-defined processes to particular company needs or to create own tailor-made processes that are specific to company business. The tool makes company decision-making processes more reliable since it includes all relevant risks and uncertainties into decision process and significantly improves the quality of company strategic planning because of the incorporation al possible scenarios of future development of the environment.

\section{ACKNOWLEDGEMENTS}

This work was supported by the grant of the Ministry of Industry of the Czech Republic, program TRIO, Tools for the innovation and optimization of company processes performance within the framework of INDUSTRY 4.0 (grant number FV30110). The paper was elaborated with the support of University of Economics and Management in Prague (VŠEM).

\section{REFERENCES}

Al Badi, K., 2019. Discrete event simulation and pharmacy process reengineering. International Journal of Health Care Quality, [e-journal] 32(2), pp.398-411. DOI: 10.1108/IJHCQA-05-2018-0105.

Caetano, A., Zacaries, M., Silva, A. and Tribolet, J., 2005. A role-based framework for business modelling. In: HICSS (Hawaii International Conference on System Sciences), Proceedings of the Proceedings of the 38th Annual Hawaii International Conference on System Sciences. Honolulu, Hawaii, USA, 09-12 March. Washington, DC, US: IEEE Computer Society.

Campbell, J. L., Quincy, C., Osserman, J. and Pedersen, O. K., 2013. Coding Indepth Semistructured Interviews: Problems of Utilization and Intercoder Reliability and Agreement. Sociological methods \& Research, [e-journal] 42(3), pp.294-320. DOI: 10.1177/0049124113500475.

Cernauskas, D. and Tarantino, A., 2009. Operational risk management with process control and business process modelling. The Journal of Operational Risk, [e-journal] 4(2), pp.3-17. DOI: 10.21314/JOP.2009.061. 
China Academy of Information and Communication Technology, 2016. China Industry Development Report 2016. Beijing: Posts and Telecom Press.

Crouhy, M., Galai, D. and Mark, R., 2014. The Essentials of Risk Management. 2nd ed. New York: McGraw-Hill Education.

Curtis, B., Kellner, M. and Over, J., 1992. Process Modelling. Communications of the ACM, [e-journal] 35(9), pp.75-90. DOI: 10.1145/130994.130998.

Damij, N., Boškoski, P., Bohanec, M. and Mileva Boshkoska, B., 2016. Ranking of Business Process Simulation Software Tools with DEX/QQ Hierarchical Decision Model. PLoS ONE, [e-journal] 11(2), e0148391. DOI: 10.1371/journal.pone.0148391.

Davila, T., Epstein, M.J. and Shelton, R., 2012. Making innovation work: how to manage it, measure it, and profit from it. Upper Saddle River, NJ: Pearson FT Press.

Dezhina, I., Ponomarev, A. and Frolov, A., 2015. Advanced Manufacturing Technologies in Russia: Outlines of a New Policy. Foresight-Russia, [e-journal] 9(1), pp.20-31. DOI: 10.17323/1995-459X.2015.1.20.31.

Gassmann, O., Frankenberger, K. and Csik, M., 2014. The Business Model Navigator. Harlow: Pearson FT Publishing.

Greasley, A., 2003. Using business-process simulation within a business-process reengineering approach. Business Process Management Journal, [e-journal] 9(4), pp.408-420. DOI: 10.1108/14637150310484481.

Hao, H., Qiao, Q., Liu, Z. and Zhao, F., 2017. Impact of Recycling on energy consumption and greenhouse gas emission from electric vehicle production: The China 2025 case. Resources, Conservation and recycling, [e-journal] 122, pp.114-125. DOI: 10.1016/j.resconrec.2017.02.005.

Havey, M., 2005. Essential Business Process Modelling. Sebastopol, CA: O'Reilly Media.

Heinrich, R., Merkle, P., Henss, J. and Paech, B., 2017. Integrating business process simulation and information system simulation for performance prediction. Software System Model, [e-journal] 16, pp.257-277. DOI: 10.1007/s10270-015-0457-1.

Kagermann, H., Wahlster, W. and Helbig, J., 2013. Recommendations for Implementing the Strategic Initiative INDUSTRIE 4.0. -- Securing the Future of German Manufacturing Industry. [pdf] München: National Academy of Science and Engineering. Available at: < http://forschungsunion.de/pdf/industrie_4_0_final_report.pdf $>$ [Accessed 16 January 2021].

Kao, H-A. and Yang, S., 2014. Service Innovation and Smart Analytics for Industry 4.0 and Big Data Environment. Procedia CIRP 16, pp.38. DOI: 10.1016/j.procir.2014.02.001. 
Kaufmann, T., 2015. Geschäftsmodelle in Industrie 4.0 und dem Internet der Dinge - Der Weg vom Anspruch in die Wirklichkeit. Wiesbaden: Springer.

Kazakova, H., Zayarky, I. and Medvedev, M., 2019. Forecasting of Financial Flows in Business systems taking into Account the Risk and Uncertainty of Interaction. In: T. Simos and $\mathrm{CH}$. Tsitouras, eds., International Conference on Numerical Analysis and Applied mathematics (ICNAAM 2018). Rhodes, Greece, 13-18 September 2018. AIP Publishing. Article No. 430021.

Kumagai, K., Araki, M. and Ono, T., 2014. Business Process Modelling Method with Hierarchical Business Variation Analysis. IEEJ Transactions on Electronics Information and Systems, [e-journal] 134(6), pp.806-813. doi:10.1541/ieejeiss.134.806.

Luo, W. and Tung, A., 1999. A framework for selecting business process modelling methods. Industrial Management \& Data Systems, [e-journal] 99(7), pp.312-319. DOI: 10.1108/02635579910262535.

Magretta, J., 2002. Why Business Models Matter. Harvard business review, 80(5), pp.86-92.

Nurcan, S., Etien, A., Kaabi, R. and Zoukar, I., 2005. A strategy driven business process modelling approach. Business Process Management Journal, [e-journal] 11(6), pp.628-649. DOI: 10.1108/14637150510630828.

Osterwalder, A. and Pigneur, Y., 2010. Business Model Generation. Hoboken, New Jersey: Wiley \& Sons.

Patig, S. and Stolz, M., 2013. A pattern-based approach for the verification of business process descriptions. Information and Software Technology, [e-journal] 55(1), pp.58-87. DOI: 10.1016/j.infsof.2012.07.002.

Pidd, M. and Carvalho, A., 2007. Simulation software: Not the same yesterday, today and forever. Journal of simulation, [e-journal] 1(1), pp.7-20. DOI: 10.1057/palgrave.jos.4250004.

Praca, I., Ramos, S., Andrade, R. da Silva, A.S. and Sica, E.T., 2019. Analysis and Simulation of Local Energy Markets. In: University of Ljubljana, Faculty of Electrical Engineering, Proceedings of 16th International Conference on The European Energy Market (EEM). Ljubljana, Slovenia, 18-20 September 2019. IEEE.

Prause, M. and Weigand, J., 2016. Industry 4.0 and Object-Oriented Development: Incremental and Architectural Change. Journal of Technology Management and Innovation, [e-journal] 11(2), pp.104-110. DOI: $10.4067 /$ S0718-2724201600020001.

Ramsauer, C., 2013. Industrie 4.0 - Die Produktion der Zukunft. WINGbusiness, 3, pp.6-12.

Rippl, T., 2005. Business Process Modelling - methods and methodologies. Systémová integrace, 12(3), pp.27-42. 
Silva, S.A., de Abreu, P.H.C. and de Amorim, F.R., 2019. Application of Monte Carlo simulation for analysis of costs and economics risks in a banking agency. IEEE Latin America Transactions, 17(3), pp.409-417.

Silver, B., 2009. BPMN Method and Style (with BPMN Implementer's Guide). 2nd ed. Aptos, CA, USA: Cody-Cassidy Press.

Silverstein, D., Samuel, P. and Decarlo, N., 2012. The innovator's toolkit: 50+ techniques for predictable and sustainable organic growth. Hoboken: John Wiley \& Sons.

Smit, J., Kreutzer, S., Moeller, C. And Carlberg, M., 2016. Policy Department A: Economic and Scientific Policy Industry 4.0. Study. [pdf] Available at: <https://www.europarl.europa.eu/RegData/etudes/STUD/2016/570007/IPOL_ST U(2016)570007_EN.pdf> [Accessed 08 September 2019].

Špaček, M. and Červený, K., 2020. Kreativní metody v inovacích. Praha: Oeconomia.

Špaček, M., 2015. Pravděpodobnostní př́stupy $k$ analýze rizik investičních projektů a jejich využití v praxi. Plzeň: NAVA - Nakladatelská a vydavatelská agentura.

Tbaishat, D., 2017. Business process modelling using ARIS: process architecture. Library management, 38(2/3), pp.88-107. DOI: 10.1108/LM-052016-0042.

Tbaishat, D., 2018. Process architecture development using Riva and ARIS: comparative study. Business Process Management Journal, [e-journal] 24(3), pp.837-858. DOI: 10.1108/BPMJ-04-2016-0086.

TIBCO, 2020. TIBCO Business Studio. [computer program] TIBCO® BPM Enterprise. Available at: <https://www.tibco.com/resources/datasheet/tibcobusiness-studio > [Accessed 19 January 2021].

Tichý, M., 2006. Ovládání rizika. Praha: C.H. Beck.

Tigkiropoulos, K., Kyratsis, P. and Dinopolulou, V., 2009. Business Process Reengineering Through Business Process Simulation: A Case Study. The Cyprus Journal of Sciences, 7, pp.23-91.

Vacík, E., Špaček, M., Fotr, J. and Kracík, L., 2018. Project Portfolio Optimization as A Part of Strategy Implementation Process in Small and Medium-Sized Enterprises: A Methodology of the Selection of Projects with The Aim to Balance Strategy, Risk and Performance. E+M Ekonomie a Management, [e-journal] 21(3), pp.107-123. DOI: 10.15240/tul/001/2018-3-007.

Wang, W. and Duffy, A.H.B., 2009. A triangulation approach for design research. In: Proceedings of ICED'09, 2, pp.275-286. Available at: <https://pure.strath.ac.uk/ws/portalfiles/portal/397405/ICED09_386_WangA_triangulation_approach_for_design_research.pdf> [Accessed 14 December 2020]. 
Wildemann, H., 2014. Cost-Engineering. Verankerung des Cost-Engineerings im Unternehmen.In: G. Schuh and V. Stich, eds. Enterprise-Integration. Springer, Berlin. pp.181-193.

Young, M. L., Buckley, S., Caswell, N., Nigam, A. and Ramachandran, B., 2020. Business Process Modelling for an Opportunity Management Process. Yorktown, NY: IBM T. J. Watson Research Center.

Zhang, Z., Liu, S. and Tang, M., 2014. Industry 4.0: Challenges and Opportunities for Chinese Manufacturing Industry. Technical Gasette, 26(6), IIIIV.

\section{ABOUT THE AUTHOR}

Miroslav Špaček ${ }^{0000-0001-6042-3249}$ (M. ̌. .) - Assoc. Prof., University of Economics and Management in Prague (VŠEM), Prague, Czech Republic, e-mail: miroslav.spacek@vsem.cz.

\section{CONFLICTS OF INTEREST}

The author declares no conflict of interest. The funders had no role in the design of the study; in the collection, analyses, or interpretation of data; in the writing of the manuscript, or in the decision to publish the results.

(C) 2021 by the authors. Submitted for possible open access publication under the terms and conditions of the Creative Commons Attribution (CC-BY) license (http://creativecommons.org/licenses/by/4.0/). 